\title{
PERANCANGAN MEDIA PEMBELAJARAN BERBASIS VIDEO TUTORIAL MENDESAIN JARINGAN LOKAL/LAN KELAS X TKJ
}

\author{
Deviana Mapicayanti ${ }^{1}$, Jamaludin ${ }^{2}$, Ahmad Fathoni ${ }^{3}$ \\ ${ }^{1,2,3}$ Program Studi Pendidikan Informatika, \\ Fakultas Matematika dan Ilmu Pengetahuan Alam, Universitas Hamzanwadi \\ Email : devimapica46@gmail.com ${ }^{1}$, jamal.ict@hamzanwadi.ac.id ${ }^{2}$, \\ ahmad.fathonis2ptk@gmail.com $^{3}$
}

\begin{abstract}
Abstrak
Tujuan penelitian ini untuk mengetahui: (1) Hasil Perancangan Media Pembelajaran Berbasis Video Tutorial Pada Materi Mendesain Jaringan Lokal/LAN Pada Siswa Kelas X TKJ di SMKN 1 Sakra, (2) besar tingkat kelayakan media pembelajaran yang dikembangkan. Penelitian ini merupakan penelitian Research and Development dengan model pengembangan ADDIE, yaitu (1) Analisys, (2) Design, (3) Development, (4) Implementation, dan (5) Evaluation. Instrumen penilaian media pembelajaran berbasis video tutorial berupa angket skala 5. Sumber data penelitian adalah 2 ahli media, 2 ahli materi, dan 33 siswa jurusan TKJ. Hasil penelitian ini adalah Perancangan Media Pembelajaran Berbasis Video Tutorial Pada Materi Mendesain Jaringan Lokal/LAN Pada Siswa Kelas X TKJ di SMKN 1 Sakra, dengan tampilan berupa intro, halaman menu, halaman profil, halaman KI/KD, 2 halaman submenu materi yaitu teori dan video, halaman materi pokok, halaman tujuan pembelajaran, dan halaman kuis. Hasil uji kelayakan Ahli Media ditinjau dari 2 aspek termasuk ke dalam kategori Sangat Layak (87\%). Dan hasil uji dari Ahli Materi masuk ke dalam kategori Sangat Layak (95\%). Berdasarkan respon pemakaian media oleh 33 siswa kelas X jurusan TKJ masuk dalam kategori Sangat Layak (83\%).
\end{abstract}

Kata Kunci: Jaringan LAN, ADDIE

\section{Abstract}

The purpose of this study was to find out: (1) The Results of Designing Learning Media Based on Video Tutorials on Material Designing Local / LAN Networks For Class X Students of TKJ at 1 Sakra Vocational High School, (2) the level of feasibility of the developed learning media. This study is Research and Development research with ADDIE development model, namely (1) Analysys, (2) Design, (3) Development, (4) Implementation, and (5) Evaluation. The assessment instrument for video tutorial-based learning media was in the form of a 5-scale questionnaire. The sources of the research data were 2 media experts, 2 material experts, and 33 students majoring in TKJ. The results of this study are the Design of Learning Media Based on Tutorial Videos on Material Designing Local / LAN Networks in Class X TKJ students at 1 Sakra Vocational High School, with a display in the form of intro, menu page, profile page, KI / KD page, 2 pages submenu material namely theory and videos, subject matter pages, learning goal pages, and quiz pages. Media Expert feasibility test results viewed from 2 aspects are categorized as Very Eligible (87\%). And the test results from Material Experts fall into the category of Very Eligible (95\%). Based on the response of media usage by 33 students of class X majoring in TKJ, it was categorized as Very Eligible (83\%).

Keywords: LAN network, ADDIE

\section{PENDAHULUAN}

SMKN (Sekolah Menengah Kejuruan Negeri) 1 Sakra merupakan sekolah kepemilikan pemerintah daerah yang berstatus negeri dengan NPSN 50202497, dengan SK pendirian sekolah 0135/O/1989 pada tanggal 10 Mei 2017. SMKN (Sekolah Menengah Kejuruan Negeri) 1 Sakra terakreditasi A dan bersertifikat ISO 9001:2008. SMKN (Sekolah Menengah Kejuruan Negeri) 1 Sakra berdiri pada tahun 1988 diatas lahan seluas 13 hektar. Pada tahun ajaran 2016/2017, sekolah ini memiliki 871 siswa, dengan komposisi 69 persen 
siswa laki-laki dan 31 persen siswa perempuan. SMKN (Sekolah Menengah Kejuruan Negeri) 1 Sakra menawarkan 10 jurusan atau paket keahlian, yaitu Teknik Kendaraan Ringan (TKR), Teknik Sepeda Motor (TSM), Teknik Komputer dan Jaringan (TKJ), Multimedia (MM), Akomodasi Perhotelan (AP), Mekanisasi Pertanian (MP), Agribisnis Ternak Unggas (ATU), Agribisnis Tanaman Pangan dan Hortikultura (ATPH), Budidaya Perikanan, dan Teknologi Pengolahan Hasil Pertanian (TPHP).

Pada salah satu jurusan tersebut, terdapat jurusan yang bergerak dibidang Ilmu Teknologi Komputer yaitu jurusan TKJ. Pada jurusan TKJ terdapat mata pelajaran Komputer dan Jaringan Dasar yang merupakan program keahlian yang harus ditempuh terlebih dahulu oleh para peserta didik di kelas X (Sepuluh), agar peserta didik lebih siap menempuh materimateri tentang jaringan komputer ketingkat kelas berikutnya. Pada mata pelajaran ini, siswa kelas X (Sepuluh) diajarkan jenis-jenis jaringan komputer, pengalamatan IP (Internet Protocol), mendesain jaringan komputer, dan dasar-dasar jaringan komputer lainnya.

Berdasarkan observasi lapangan yang dilakukan di SMKN (Sekolah Menengah Kejuruan Negeri) 1 Sakra berupa wawancara dengan salah satu Guru TKJ (Teknik Komputer Dan Jaringan) yang mengampu mata pelajaran Komputer dan Jaringan Dasar diperoleh bahwa, Kurikulum yang digunakan di SMKN (Sekolah Menengah Kejuruan Negeri) 1 Sakra adalah Kurikulum 2013. Siswa dituntut untuk lebih aktif dan mandiri dalam mencari materi pembelajaran. Guru melakukan demonstrasi hanya pada saat kegiatan praktikum. Dalam kegiatan belajar mengajar, sekolah belum mencoba menggunakan media pembelajaran berbasis video tutorial dan bahkan juga jarang ada Guru yang membuat media pembelajaran berbasis video tutorial, khususnya pada mata pelajaran Komputer dan Jaringan Dasar pada jurusan TKJ (Teknik Komputer dan Jaringan). Maka dari itu, proses pembelajaran yang dilakukan masih menggunakan media Laptop dan $L C D$ Proyektor tanpa pemanfaatan yang lebih kreatif. Pada proses pembelajaran mata pelajaran Komputer dan Jaringan Dasar terlihat juga bahwa pada saat praktik ketika Guru melakukan demonstrasi hanya dilakukan sekali tidak berulang-ulang sehingga siswa yang kurang memperhatikan atau kurang jelas masih terlihat bingung.

Untuk mengatasi masalah tersebut, usaha yang harus dilakukan Guru adalah memanfaatkan teknologi informasi seperti Komputer beserta aplikasi Multimedia lainnya dalam penggunaan media pembelajaran yang dapat menunjang proses belajar mengajar sehingga Guru tidak hanya menggantungkan dengan demonstrasi tetapi bisa diganti dengan video tutorial yang dapat diputar berulang-ulang. Penggunaan media pembelajaran berbasis video tutorial ini diharapkan akan sangat membantu dan mempermudah proses pembelajaran untuk Siswa maupun Guru. Dengan demikian, Guru tidak harus menjelaskan secara berulangulang sehingga proses pembelajaran dapat berlangsung lebih menarik, efektif dan efisien.

\section{METODE}

Penelitian ini menggunakan metode $R \& D$ (Research and Development) atau disebut juga metode penelitian dan pengembangan adalah metode penelitian yang digunakan untuk menghasilkan produk tertentu, dan menguji keefektifan produk tersebut. Penilitian ini menggunakan model ADDIE sebagai model pengembangan media pembelajaran, model ADDIE merupakan singkatan dari (1) Analysis, (2) Design, (3) Development, (4) Implementation, (5) Evaluatio.( Muliyatiningsih, 2013:199).

Lima tahapan dalam model ADDIE tersebut kemudian dikembangkan untuk menjadi langkah-langkah dalam melakukan pengembangan media pembelajaran berbasis video tutorial. Adapun 5 tahapan ADDIE dapat dijabarkan sebagai berikut :

Analisis (Analysis) Pada tahap ini dilakukan identifikasi kebutuhan yang dihasilkan dari observasi dan wawancara awal. Pada penelitian ini, observasi dilakukan untuk 
mengetahui kondisi siswa dari aspek sikap selama mengikuti pembelajaran Komputer dan Jarigan Dasar menggunakan media dari Guru. Wawancara dengan Guru dilakukan untuk mengetahui kondisi siswa dari aspek pengetahuan atau hasil belajarnya, serta permasalahan lain yang berkaitan dengan media pembelajaran. Hasil wawancara tentang Silabus dapat digunakan untuk menentukan materi yang akan disampaikan pada pengembangan media.

Desain tahap yang selanjutnya dilakukan adalah tahap desain atau perancangan produk yang meliputi tahap berikut: 1) Menentukan standar kompetensi pada materi pokok mendesain jaringan Lokal/LAN (Local Area Network) 2) Menentukan kompetensi dasar dari materi pokok mendesain jaringan Lokal/LAN (Local Area Network) 3) Membuat Flowchart 4) Membuat Storyboard.

Tahap Pengembangan tahap pengembangan ini terdapat 3 kegiatan yang dilakukan yaitu sebagai berikut:

1) Memprogram Media Pembelajaran

Perancangan media pembelajaran berbasis video tutorial diprogram menggunakan Software Adobe Flash CS6. Di dalam pemrograman media pembelajaran ini, perancang mengumpulkan bahan-bahan seperti background yang digunakan untuk tampilan media pembelajaran, penggunaan animasi, tombol-tombol navigasi, pengaturan sound effect pada scene atau halaman dan tombol-tombol navigasi, banyaknya jumlah scene atau halaman serta melakukan pengkodingan untuk menghubungkan antar scene, tombol dan layer. Produk yang dikembangkan berupa program media pembelajaran interaktif dengan format Flash Movie dengan ekstensi .swf yang bisa secara langsung dijalankan pada komputer/laptop tanpa diinstal terlebih dahulu seperti program aplikasi secara umum.

2) Menyusun Materi Pembelajaran

Penyusunan materi pembelajaran dimulai dengan menentukan Standar Kompetensi pada Silabus mata pelajaran Komputer dan Jaringan Dasar yaitu mengenai mendesain jaringan lokal/LAN (Local Area Network). Kemudian dijabarkan menjadi beberapa materi pokok yaitu LAN (Local Area Network), macam-macam perangkat jaringan, dan prosedur pembuatan simulasi jaringan sederhana pada Packet Tracer. Dimana materi pokok tersebut akan menjadi isi pembahasan materi pada media pembelajaran baik materi teori maupun materi video.

3) Memproduksi Video dan Audio

Proses produksi video menggunakan bantuan Software Camtasia 7 dengan melakukan record the screen pada saat membuat video mengenai pengenalan workspace Cisco Packet Tracer dan mendesain jaringan LAN (Local Area Network) sederhana dengan menggunakan Software Cisco Packet Tracer. Kemudian dilanjutkan dengan merekam suara narator menggunakan aplikasi perekam suara pada handphone yang disesuaikan dengan durasi waktu pada video. Selanjutnya pengolahan dilakukan dengan menggabungkan hasil dari video, suara narator maupun backsound menggunakan Software Camtasia 7.

d. TahapImplementasi

Pada tahap implementasi dimana kegiatan yang dilakukan adalah penerapan produk yang dikembangkan berupa media pembelajaran berbasis video tutorial. Disini produk diuji cobakan selama dua kali pertemuan dengan melibatkan siswa SMKN (Sekolah Menengah Kejuruan Negeri) 1 Sakra kelas X (Sepuluh) TKJ (Teknik Komputer dan Jaringan). Pada tahap ini, siswa akan belajar menggunakan media pembelajaran berbasis video tutorial. Kemudian siswa akan menilai media pembelajaran tersebut dengan menggunakan angket untuk mengetahui bagaimana pendapat siswa terhadap media pembelajaran berbasis video tutorial. 


\section{e. Tahap evaluasi (evaluation)}

Pada tahap ini akan dilakukan evaluasi yang meliputi validasi instrumen, validasi produk, dan revisi sesuai dengan komentar dan saran dari ahli. Angket akan diberikan kepada ahli materi, ahli media dan siswa untuk menilai apakah produk berupa media pembelajaran berbasis video tutorial yang dibuat layak atau tidak. Dengan angket tersebut, akan dikumpulkan data dari hasil penilaian akhir terhadap kelayakan media untuk mendapatkan kesimpulan mengenai kualitas dari media yang dirancang.

Instrumen pengumpulan data yang digunakan adalah observasi (pengamatan), interview (wawancara), kuesioner (angket). Angket merupakan teknikpengumpulan data dengan cara mengajukan pertanytaan tertulis untuk dijawab secara tertulis pula oleh responden. Teknik analisa data yang digunakan adalah analisis kelayakan. Analisis kelayakan digunakan untuk mengetahui penilaian pada proses validasi. Uji reliabilitas instrumen pada penelitian ini menggunakan teknik Alpha Cronbach. Dikarenakan penelitian ini menggunakan instrumen berupa kuesioner/angket. Berikut adalah rumus Alpha Cronbach (Sugiyono, $2013: 365$ )

$$
r_{11}=\left(\frac{k}{k-1}\right)\left(1-\frac{\sum \sigma_{b}^{2}}{\sigma_{t}^{2}}\right)
$$

Rumus untuk variansi total.

$$
\sigma^{2}=\frac{\sum \mathrm{X}^{2}-\frac{\left(\sum \mathrm{X}\right)^{2}}{\mathrm{~N}}}{\mathrm{~N}}
$$

Langkah selanjutnya adalah menghitung persentase uji realibilitas instrumen dan untuk melihat tingkat uji relaibilitas instrumen dapat dilihat pada tabel 1.

Tabel.1 Tingkat Realiablitas Instrumen

\begin{tabular}{ccc}
\hline No & Koefisien & Tingkat Hubungan \\
\hline 1 & $0,000-0,200$ & Sangat rendah \\
2 & $0,200-0,400$ & Rendah \\
3 & $0,400-0,600$ & Agak Rendah \\
4 & $0,600-0,800$ & Cukup \\
5 & $0,800-1,000$ & Tinggi \\
\hline
\end{tabular}

Presentase kualitas penilaian validator dengan menggunakan rumus sebagai berikut :

$$
\text { Persentase Kelayakan(\%) } \frac{\text { Skor yang diperoleh }}{\text { skor yang diharapkan }} \text { x 100\% }
$$

Tabel 2. Kategori Pencapaian Kelayakan

\begin{tabular}{ccc}
\hline No & $\begin{array}{c}\text { Presentase } \\
\text { Pencapaian }\end{array}$ & $\begin{array}{c}\text { Klasifikasi } \\
\text { Kelayakan }\end{array}$ \\
\hline 1 & $81-100 \%$ & Sangat Layak \\
2 & $61-80 \%$ & Layak \\
3 & $41-60 \%$ & Cukup Layak \\
4 & $21-40 \%$ & Kurang Layak \\
5 & $0-20 \%$ & Tidak Layak \\
\hline
\end{tabular}

(Arikunto, 2010: 44) 


\section{HASIL DAN PEMBAHASAN}

\section{Hasil}

a) Ahli Media

Untuk ahli media terdapat 2 aspek yang dinilai yaitu aspek Tampilan Media dan Bahasa, adapun data dari Ahli media dapat dilihat pada tabel 3 sebagai berikut.

Tabel 3. Data Persentase Ahli Media

\begin{tabular}{clcc}
\hline No & \multicolumn{1}{c}{ Presentase Pencapaian } & Persentase & Kategori \\
\hline 1 & Tampilan Media & $88 \%$ & Sangat Layak \\
2 & Bahasa & $85 \%$ & Sangat Layak \\
& Rerata Persentase & $87 \%$ & Sangat Layak \\
\hline
\end{tabular}

Berdasarkan tabel diatas bahwa untuk persentase Ahli Media termasuk dalam kategori Sangat Layak.

b) Ahli Materi

Untuk ahli materi terdapat 3 aspek yang dinilai yaitu aspek Materi, Aspek Konstruksi, dan Aspek Bahasa, adapun data dari Ahli materi dapat dilihat pada tabel 4 sebagai berikut .

Tabel 4. Data Presentase Ahli Materi

\begin{tabular}{clcc}
\hline No & \multicolumn{1}{c}{ Presentase Pencapaian } & Persentase & Kategori \\
\hline 1 & Aspek Materi & $95 \%$ & Sangat Layak \\
2 & Aspek Konstruksi & $96 \%$ & Sangat Layak \\
3 & Aspek Bahasa & $93 \%$ & Sangat Layak \\
& Rerata Persentase & $95 \%$ & Sangat Layak \\
\hline
\end{tabular}

Berdasarkan tabel diatas bahwa untuk presentase Ahli Materi termasuk dalam kategori Sangat Layak.

c) Pengguna

Untuk pengguna terdapat 2 aspek yang dinilai yaitu aspek Tampilan Media dan Kemanfaatan, adapun data dari Pengguna dapat dilihat pada tabel 5 sebagai berikut :

Tabel 5. Data Presentase Pengguna

\begin{tabular}{clc}
\hline No & \multicolumn{1}{c}{ Presentase Pencapaian } & Persentase \\
\hline 1 & Tampilan Media & $62 \%$ \\
2 & Kemanfaatan & $21 \%$ \\
& Rerata Persentase & $83 \%$ \\
\hline
\end{tabular}

Berdasarkan tabel diatas bahwa untuk presentase Pengguna termasuk dalam kategori Sangat Layak.

\section{Pembahasan}

Validasi oleh ahli media mencakup 2 aspek yang dibagi dalam beberapa indikator. Aspek-aspek tersebut adalah aspek Tampilan Media dan aspek Bahasa. Berdasarkan hasil analisa data hasil Persentase dari kedua aspek ahli media tersebut didapatkan nilai Persentase kelayakan total dari ahli media sebesar 87\%, hasil tersebut apabila dipresentasikan menjadi sebuah keterangan maka didapatkan kriteria yang Sangat Layak untuk digunakan.

Validasi oleh ahli materi mencakup tiga aspek yang dibagi dalam beberapa indikator. Aspek-aspek tersebut adalah aspek Materi, aspek Konstruksi, dan Bahasa. Berdasarkan hasil analisa data, pada ketiga aspek tersebut didapatkan nilai Persentase kelayakan total dari ahli materi sebesar 95\%, hasil tersebut apabila dipresentasikan menjadi sebuah keterangan maka didapatkan kriteria yang Sangat Layak untuk digunakan dari segi isi materi media pembelajaran yang dikembangkan. 
Sebelum dilakukan uji coba lapangan/pengguna, angket/instrumen untuk pengguna dikenakan uji validitas dan reliabilitas. Uji tersebut sebagai perbandingan untuk mengetahui kevalidan dari angket/instrumen sebelum produk direvisi dan sesudah produk direvisi. Angket yang diuji validitas dan reliabilitas berisi 20 butir pernyataan yang terdiri dari 2 indikator yaitu tampilan media dan kemanfaatan. Hasil uji validitas angket/instrumen yang pertama atau sebelum dilakukan revisi pada media pembelajaran berbasis video tutorial menunjukkan ada 4 item instrumen yang tidak valid dengan hasil uji reliabilitas dari instrumen menunjukkan koefisien reliabilitas $\mathbf{0 , 7 1 3}$ dengan kategori Cukup. Pada uji validitas angket/instrumen yang kedua atau sesudah dilakukan revisi pada media pembelajaran berbasis video tutorial menunjukkan semua item instrumen memenuhi batas minimal kevalidan yaitu $\mathbf{0 , 3 5 5}$. Hasil uji reliabilitas dari instrumen menunjukkan koefisien reliabilitas $\mathbf{0 , 8 3 6}$ dengan kategori Tinggi.

Hasil pengolahan data ujicoba lapangan didapatkan Persentase total kelayakan media oleh pengguna sebesar $\mathbf{8 3 \%}$. Hasil tersebut apabila diinterpretasikan termasuk didalam kategori Sangat Layak untuk digunakan. Dari hasil data tersebut menunjukkan bahwa siswa kelas X (Sepuluh) jurusan TKJ (Teknik Komputer dan Jaringan) menyatakan media pembelajaran berbasis video tutorial Sangat Layak untuk digunakan sebagai media pembelajaran pada materi Mendesain Jaringan Lokal/LAN (Local Area Network).

\section{SIMPULAN}

Berdasarkan hasil penelitian dan pembahasan tentang perancangan media pembelajaran berbasis video tutorial pada mata materi mendesain jaringan Lokal/LAN (Local Area Network), maka dapat disimpulkan : (1) Media pembelajaran berbasis video tutorial yang di terapkan mengunakan aplikasi Adobe Flash CS6 untuk siswa kelas X jurusan TKJ di implementasikan dari model ADDIE. (2) Media pembelajaran berbasis video tutorial pada materi mendesain jaringan Lokal/LAN (Local Area Network) berdasarkan 2 ahli media masuk kategori Sangat Layak digunakan dengan persentase kualitas media 87\% pada semua aspek media.(3) Berdasarkan ahli materi masuk kategori Sangat Layak digunakan dengan persentase kualitas materi dalam media 95\%. Berdasarkan hasil dari responden, bahwa respon siswa terhadap Media pembelajaran berbasis video tutorial pada materi mendesain jaringan Lokal/LAN (Local Area Network) siswa kelas X jurusan TKJ dengan kategori Tinggi karena memiliki presentasi koefisien reliabilitas sebanyak $\mathbf{0 . 8 3 6}$.

\section{REFERENSI}

Arikunto, S. (2010). Prosedur penelitian: Suatu pendekatan praktik. Jakarta: PT Rineka Cipta.

Arsyad, A. (2011). Media pembelajaran. Jakarta: PT. RajaGrafindo Persada.

Binanto, I. 2010. Multimedia digital: Dasar teori dan pengembangannya. Yogyakarta: CV. Andi Offset.

Daryanto. (2013). Media Pembelajaran, Peranannya Sangat Penting dalam Mencapai Tujuan Pembelajaran. Yogyakarta: Gava Media.

Khanifatul. (2013). Pembelajaran inovatif, strategi mengelola kelas secara efektif dan menyenangkan. Jogjakarta: Ar-Ruzz Media.

Mulyatiningsih, E. (2013). Metode penelitian terapan bidang pendidikan. Bandung: Alfabeta. 
Volume 2, Nomor 2, Desember 2018

Rusman. (2012). Belajar dan Pembelajaran Berbasis Komputer, Mengembangkan Profesionalisme Guru Abad 21. Bandung: Alfabeta.

Sanjaya, W. (2012). Perencanaan dan desain sistem pembelajaran. Jakarta: Kencana Prenada Media Group.

Setiawan, B. (2008). Agenda Pendidikan Nasional. Jogjakarta: Ar-Ruzz Media.

Sugiyono. (2013). Metode penelitian kuantitatif, kualitatif dan R\&D. Bandung: Alfabeta. 